\title{
BMJ Open Loddon Mallee healthcare worker COVID-19 study - protocol for a prospective cohort study examining the health and well-being of rural Australian healthcare workers during the COVID-19 pandemic
}

\author{
Mark McEvoy, ${ }^{1}$ Carol Parker (1) , ${ }^{2}$ Angela Crombie, ${ }^{2}$ Timothy C Skinner, ${ }^{1}$ \\ Stephen Begg, ${ }^{1}$ Peter Faulkner, ${ }^{2}$ Anne McEvoy, ${ }^{3}$ Laura Bamforth, ${ }^{2}$ \\ Gabriel Caccaviello ${ }^{4}$
}

To cite: McEvoy M, Parker C, Crombie A, et al. Loddon Mallee healthcare worker COVID-19 study—protocol for a prospective cohort study examining the health and well-being of rural Australian healthcare workers during the COVID-19 pandemic. BMJ Open 2021;11:e050511. doi:10.1136/ bmjopen-2021-050511

- Prepublication history and additional supplemental material for this paper are available online. To view these files, please visit the journal online. (http://dx.doi.org/10.1136/ bmjopen-2021-050511)

Received 22 February 2021 Accepted 26 July 2021

Check for updates

(C) Author(s) (or their employer(s)) 2021. Re-use permitted under CC BY-NC. No commercial re-use. See rights and permissions. Published by BMJ.

For numbered affiliations see end of article.

Correspondence to

Mark McEvoy;

m.mcevoy@latrobe.edu.au

\section{ABSTRACT}

Introduction The COVID-19 pandemic is creating immense psychosocial disturbance. While global, broadbased research is being conducted, little is known about the effects of the COVID-19 pandemic on health and well-being or how protective and resilience factors influence the human response in Australian rural and regional communities. Rural and regional communities often have less resources to deal with such public health emergencies and face additional environmental adversity. Healthcare workers, including those in rural and regional areas, have felt the immediate impacts of COVID-19 in a multitude of ways and these impacts will continue for years to come. Therefore, this study aims to describe and understand the impacts of the COVID-19 pandemic on the rural and regional healthcare workforce within the Loddon Mallee region, Victoria, Australia.

Methods and analysis This prospective cohort of rural and regional healthcare workers will be recruited and followed over 3 years to examine the effects of the COVID-19 pandemic on their health and well-being. Selfadministered online questionnaires will be administered every 6 months for a 36 -month period. Multiple outcomes will be assessed; however, the primary outcomes are emotional health and well-being and psychological resilience. Emotional health and well-being will be measured using validated instruments that will assess multiple domains of the emotional health and well-being continuum.

Linear and logistic regression and latent growth curve modelling will be used to examine the association between baseline and follow-up participant emotional health, wellbeing and resilience while adjusting for potentially timevarying confounding variables. Participant characteristics measured at baseline will also be tested for association with incident health, morbidity, mortality and health service utilisation outcomes at follow-up.

Ethics and dissemination Ethical approval has been obtained through the Bendigo Health Human Research Ethics Committee. The study findings will be disseminated
Strengths and limitations of this study

- This large prospective cohort study will examine the impact of the COVID-19 pandemic on the health and well-being of the healthcare workforce in regional and rural Victoria, Australia, which to date has been largely unexplored.

- The longitudinal study design will allow changes in mental health and well-being over time to be measured, defining the temporal sequence of events, and providing stronger evidence for a causal association with risk factors.

- Latent growth curve modelling will allow trajectories of psychological distress and resilience (eg, resilient, chronic distress, recovered and delayed recovery) to be identified; predictors of each class will be examined by incorporating various indicators of resilience into the models.

- Non-English speaking people were excluded from the study, however the prevalence of this is very low in the Loddon Mallee region of Victoria, and even lower in the healthcare workforce.

- The representativeness nature of the sample is limited to the Loddon Mallee region of rural and regional Victoria, Australia.

through international conferences, international peerreviewed journals and social media.

Trial registration number ACTRN12620001269921.

\section{BACKGROUND}

Context

With the first reports of the global COVID-19 pandemic in December of 2019, and the first case in Australia recorded on 13 January 2020; the situation quickly escalated to declaration of a 'Public Health Emergency' by the WHO 
on 30 January 2020. ${ }^{1}$ Every person has been impacted by COVID-19 in some way. This highly infectious virus exposed healthcare workers to unprecedented situations, enabling the potential for immediate and ongoing negative mental health effects and health-related behaviours. Healthcare workers both endured the severe lockdowns and social restrictions that took place around Australia to reduce transmission, and they also had to cope with the volume of infected cases and the risks to themselves and fear of transmitting the virus to their immediate family. ${ }^{2}$

Within a 20-year span, there has been several viral epidemics of this level. ${ }^{3}$ Considering this and the magnitude of similar problems that arose across health services, including exposure concerns, worker fatigue and limited diagnostic tests globally ${ }^{4}$ for each of these outbreaks, the scientific community needs to provide factual, clear and timely information to better manage and support healthcare workers. ${ }^{5}$ Recent findings suggest that regardless of the volume of cases or deaths, healthcare workers are vulnerable to both physical and psychosocial harm from the COVID-19 pandemic. ${ }^{6}$

Although there are data on the impacts of the COVID-19 pandemic on healthcare workers from other countries that include metropolitan, regional and rural populations, ${ }^{3} 7-11$ there is a scarcity of data on regional and rural populations in Australia. To the best of the authors' knowledge, at the time of writing, three COVID19-related healthcare worker studies have been published in Australia ${ }^{12-14}$ and only one of these included healthcare workers from rural and regional communities. ${ }^{13}$ Although the COVID-19 pandemic has impacted larger metropolitan health services they are often better equipped than the smaller rural and regional health services. They have a larger pool of experienced health professionals and resources with which to meet the shortterm and long-term pressures that challenge the healthcare system in times of intensified pressure such as the current COVID-19 crisis.

The lack of understanding of the effects of the COVID-19 pandemic on rural and regional healthcare workers and their communities is detrimental for the public health of these communities. Due to the relatively small population size of rural communities, the health service is often the largest employer and the workforce touch so many of the community directly through their family and personal contacts, thus the impact on healthcare workers has more direct impact on the community generally than is the case in metropolitan areas. As such a significant and vulnerable group of regional and rural healthcare workers, clinical and non-clinical are being neglected, thus calling for urgent targeted clinical and policy strategies for these extraordinary times.

\section{Rationale}

Like other pandemics and emerging disease outbreaks, COVID-19 is creating immense psychosocial disturbance. While global, broad-based research is being conducted, little is known about the effects of the COVID-19 pandemic on health and well-being or how protective/resilience factors influence the human response in Australian rural and regional communities who often have less resources and face additional adversity in the form of drought and fire disasters.

This study presents a unique opportunity to conduct rigorous longitudinal analyses with an exclusively rural and regional focus. Longitudinal research of this type has rarely been undertaken in a historically underrepresented rural and regional population, within the Australian context. Therefore, this study aims to describe and understand the impacts of the COVID-19 pandemic on the healthcare workforce across multiple health services in rural and regional Victoria, Australia.

\section{STUDY AIMS}

\section{Research aims}

This study aims to examine the impacts of the COVID-19 pandemic on the rural and regional healthcare workforce within the Loddon Mallee region, Victoria, Australia.

\section{Objectives}

- To use a longitudinal study design to explore and describe the health and well-being impacts of the COVID-19 pandemic among a large rural and regional healthcare worker cohort.

- To identify protective/resilience factors, at the individual, organisation and community level that predict better physical and mental health outcomes for healthcare workers. Evidence-based resilience interventions may then be implemented in the future to improve the workforce response to major disruptions such as the COVID-19 pandemic.

- Inform policy options to support rural and regional healthcare workers in responding to major disruptions such as the COVID-19 pandemic.

\section{METHODS AND ANALYSIS}

\section{Study design}

A prospective cohort of healthcare workers will be recruited and followed over 3 years to examine the effects of the COVID-19 pandemic on the health and well-being of these workers.

\section{Setting}

The reference population for this study is rural and regional Australian healthcare workers. The source population will be healthcare workers within rural and regional Victoria. The sampling frame is healthcare workers currently working within the Loddon Mallee region. This includes all people who work in healthcare from participating health services within the Loddon Mallee region. The Loddon Mallee region was chosen for this study as it consists of a mix of large regional and smaller rural health services and has a broadly similar demographic profile to the rest of the Victorian rural and regional healthcare workforce in terms of age, gender and profession. ${ }^{15}$ The 

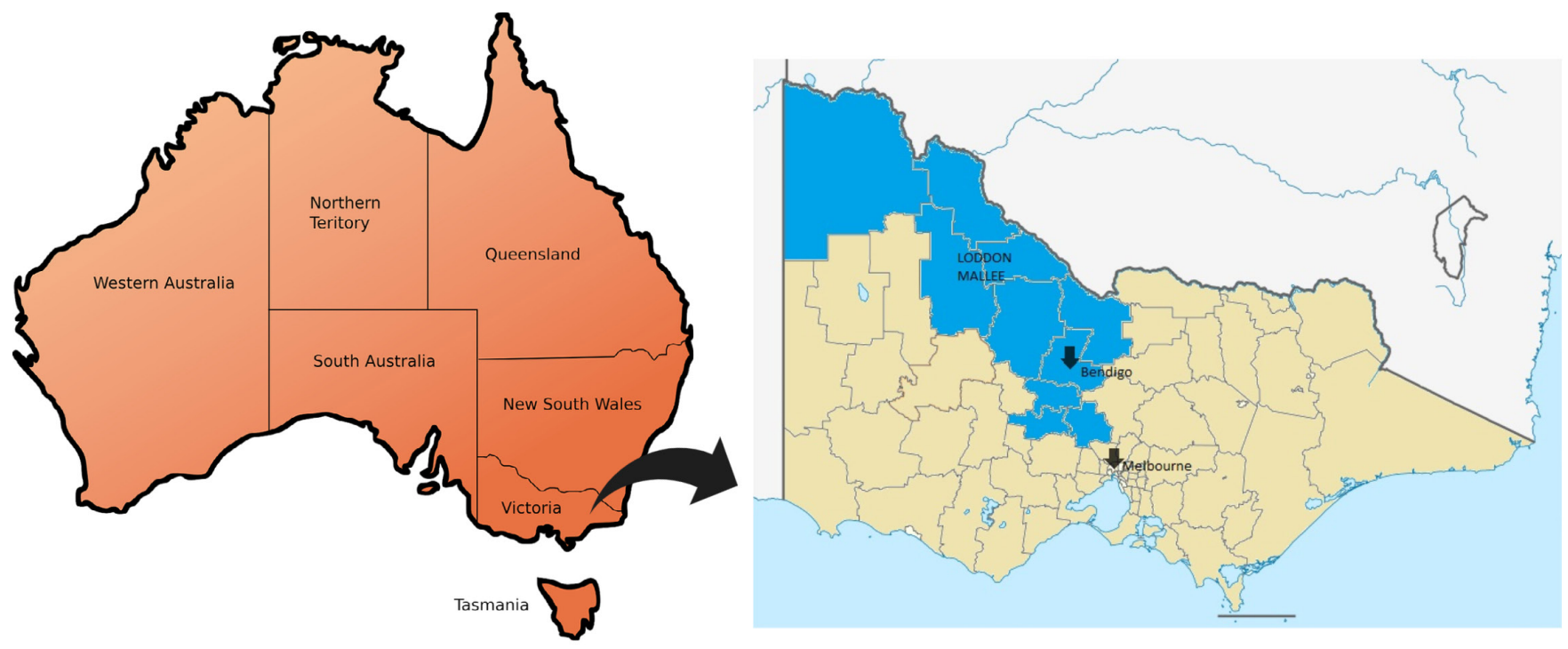

Figure 1 Location of the participating healthcare services and Modified Monash geographical classification overview within the Loddon Mallee region, Victoria, Australia.

Loddon Mallee region covers one quarter of the landmass of north central Victoria ${ }^{16}$ and in 2019 had a population of $336270^{17}$ (figure 1). Of the towns comprising the Loddon Mallee region, $86 \%$ of postcodes are designated within the Modified Monash Model (MM) ${ }^{18} 3-5$ classifications with small rural towns (MM5) making up the majority of the region.

All healthcare workers will be invited to participate from 19 rural and regional health services, five community health centres and the Murray Primary Health Network (Murray PHN) with a combined workforce of 14511 people. The Murray PHN, covering an area of almost 100000 square kilometres in northern Victoria, works directly with primary healthcare providers including general practitioners and other health providers such as hospitals. ${ }^{17}$

\section{Eligibility criteria}

All eligible healthcare workers at each participating Loddon Mallee health service will be invited to participate in the study. Healthcare worker is defined as a person who is employed or volunteering as a health service provider or health management and support worker.

\section{Inclusion}

- Age 18 or over

- Currently employed or volunteering as a health service provider or health management and support worker in a participating healthcare service in the Loddon Mallee region.
Ability to provide informed consent

\section{Exclusion}

- Inability to use electronic devices (required to complete the questionnaire)

- Non-English-speaking people.

\section{RECRUITMENT}

\section{Data collection methods}

The study commenced in November 2020 and data collection will continue until December 2023. An online selfadministered questionnaire will be conducted at baseline and every 6 months for a 36-month period. At 3, 9 and 15 months, a smaller questionnaire containing selected instruments will also be administered so that short-term changes in important mental health and well-being outcomes are not missed. A summary of the study outcomes, outcome measurement instruments and measurement timepoints is provided in table 1 . The baseline questionnaire is available as a online supplemental file.

Potential study participants from the Loddon Mallee healthcare workforce will be identified from organisational staff email lists. One week prior to recruitment a general prenotification email will be sent to all staff members informing them that they will soon receive an invitation to participate in the study. This email will highlight the importance of the study and how the information will be used to help the workforce and to make changes to improve the response to future pandemics and disasters. 
Table 1 Outcomes, outcome measuring instruments and measurement timepoints

\begin{tabular}{|c|c|c|c|c|c|c|c|c|c|c|c|}
\hline \multirow[b]{2}{*}{ Outcome category } & \multirow[b]{2}{*}{ Specific outcome } & \multirow[b]{2}{*}{ Outcome measuring instruments } & \multicolumn{9}{|c|}{ Study timepoint (months) } \\
\hline & & & 0 & 3 & 6 & 9 & 12 & 15 & 18 & 24 & 30 \\
\hline \multirow[t]{2}{*}{ Mortality } & $\begin{array}{l}\text { Linkage to National Death } \\
\text { Index (NDI) }\end{array}$ & NDI & & & & & & & & & \\
\hline & $\begin{array}{l}\text { Disease-specific causes of } \\
\text { death }\end{array}$ & $\begin{array}{l}\text { Disease-specific cause of death } \\
\text { database }\end{array}$ & & & & & & & & & \\
\hline \multirow{11}{*}{$\begin{array}{l}\text { Clinical and } \\
\text { physiological function }\end{array}$} & Morbidity (health diagnoses) & Data linkage & & & & & & & & & \\
\hline & $\begin{array}{l}\text { Height and weight (for } \\
\text { calculating Body Mass Index) }\end{array}$ & Self-report (2-items) & & & & & & & & & \\
\hline & $\begin{array}{l}\text { Disease-specific symptoms } \\
\text { (eg, gut symptoms) }\end{array}$ & $\begin{array}{l}\text { Psychosomatic Symptom Checklist } \\
\text { (17-items) }^{56}\end{array}$ & & & & & & & & & \\
\hline & Medication use & Health record linkage & & & & & & & & & \\
\hline & Hearing & Self-report (1-item) & & & & & & & & & \\
\hline & Vision & Self-report (1-item) & & & & & & & & & \\
\hline & Screening & Self-report (9-items) & & & & & & & & & \\
\hline & $\begin{array}{l}\text { Delayed or postponed } \\
\text { screening }\end{array}$ & Self-report (1-item) & & & & & & & & & \\
\hline & Contraception use & Self-report (1-item) & & & & & & & & & \\
\hline & Hormone replacement use & Self-report (1-item) & & & & & & & & & \\
\hline & Reproductive history & Self-report (7-items) & & & & & & & & & \\
\hline $\begin{array}{l}\text { Physical function } \\
\text { (separate to physical } \\
\text { activity) }\end{array}$ & $\begin{array}{l}\text { Physical functioning/ } \\
\text { functional living (eg, ADLs), } \\
\text { participation, satisfaction } \\
\text { with physical function }\end{array}$ & $\begin{array}{l}\text { SF-12 Physical Component } \\
\text { Summary Score }\end{array}$ & & & & & & & & & \\
\hline \multirow{13}{*}{$\begin{array}{l}\text { Emotional health and } \\
\text { well-being }\end{array}$} & $\begin{array}{l}\text { Post-traumatic stress } \\
\text { disorder }\end{array}$ & $\begin{array}{l}\text { Impact of Events Scale-6 (IES-6) } \\
(6 \text {-items })^{40}\end{array}$ & & & & & & & & & \\
\hline & Depressive symptoms & $\begin{array}{l}\text { Patient Health Questionnaire } \\
(9 \text {-items })^{41}\end{array}$ & & & & & & & & & \\
\hline & Stress & Perceived Stress Scale (10-items) ${ }^{42}$ & & & & & & & & & \\
\hline & Suicide ideation & $\begin{array}{l}\text { Suicidal Behaviours Questionnaire- } \\
\text { Revised (4-items) }{ }^{43}\end{array}$ & & & & & & & & & \\
\hline & Resilience & Brief Resilience Scale (6-items) $)^{55}$ & & & & & & & & & \\
\hline & Fatigue & SF-12 Vitality Scale (1-item) ${ }^{44}$ & & & & & & & & & \\
\hline & Hope & $\begin{array}{l}\text { The Adult State (Snyder) Hope } \\
\text { Scale (6-items) }{ }^{45}\end{array}$ & & & & & & & & & \\
\hline & Self-efficacy & $\begin{array}{l}\text { General Self-efficacy Scale } \\
(10 \text {-items })^{46}\end{array}$ & & & & & & & & & \\
\hline & Coping & Brief COPE (28-items) ${ }^{47}$ & & & & & & & & & \\
\hline & Worry & Penn State Worry Questionnaire ${ }^{48}$ & & & & & & & & & \\
\hline & Purpose & $\begin{array}{l}\text { Mental Health Continuum Short } \\
\text { Form }^{49}\end{array}$ & & & & & & & & & \\
\hline & Optimism & $\begin{array}{l}\text { Two items from Life Orientation } \\
\text { Test-Revised }(2 \text {-items })^{50}\end{array}$ & & & & & & & & & \\
\hline & Compassion & $\begin{array}{l}\text { Self-compassion Scale: Short Form } \\
(12 \text {-item })^{66}\end{array}$ & & & & & & & & & \\
\hline
\end{tabular}


Table 1 Continued

Cognitive function

Social function

Lifestyle

Health service utilisation

Sociodemographic

Economic/financial (including ability to manage on income)

Study timepoint (months)

Outcome measuring instruments

\begin{tabular}{lllllllll}
\hline 0 & 3 & 6 & 9 & 12 & 15 & 18 & 24 & 30 \\
\hline
\end{tabular}

management behaviour

Childhood trauma

Impact of events

Mindfulness

Family history of mental disorder

Personality/temperament/ character

Attention and executive function

Social support including perceived availability

Social isolation and loneliness

Quality of life measures

General role functioning

Life events

Perceived Control

Positive aspects of staying home

Physical activity

Alcohol use/misuse

Smoking

Sleep (duration and quality) and insomnia

Diet quality

Supplement use

Health promoting behaviour pandemic

Family functioning

Specific services

Education, income, housing, Specific questions (33-items) etc.

Financial hardship $(9 \text {-items })^{73}$
Self-control and Self-management Behaviour Scale (16-item) ${ }^{67}$

Childhood Trauma QuestionnaireShort Form (13-items) ${ }^{52}$ Impact of Life Events-IES-6 ${ }^{40}$

Mindfulness Attention Awareness Scale $\left(6\right.$-items) ${ }^{53}$

Self-report list for first-degree relatives

Big 5 Inventory-Short form $(30 \text {-items })^{54}$

Medical Outcomes Study (MOS) (6-items cognition questions) $^{68}$

Duke Social Support Index $(11 \text {-items })^{69}$

UCLA Loneliness Scale Version 3 $(3 \text {-items })^{70}$

SF-12 (12-items) ${ }^{44}$

SF-12 (12-items) $)^{44}$

Recent Life Events Questionnaire (12-items)

Life Control Scale ${ }^{51}$

Specific questions (eg, more time with family, more time with hobbies, etc.) (16-items)

International Physical Activity Questionnaire short form (7-items) ${ }^{71}$

Alcohol use disorders identification test - C (AUDIT-C) alcohol use disorders identification test ${ }^{72}$

American Cancer Society questions

Pittsburgh Sleep Quality Index $(10 \text {-items })^{74}$

Short diet quality questions $(14 \text {-items })^{75}$

Self-report (4-items)

Health-Promoting Lifestyle Profile II $(52-\text { items })^{76}$

Specific questions (26-items)

General Functioning Index of the McMaster Family Assessment Device (6-items) ${ }^{77}$

List of services (1-item)

Four questions in household, sociodemographic and neighbourhood section

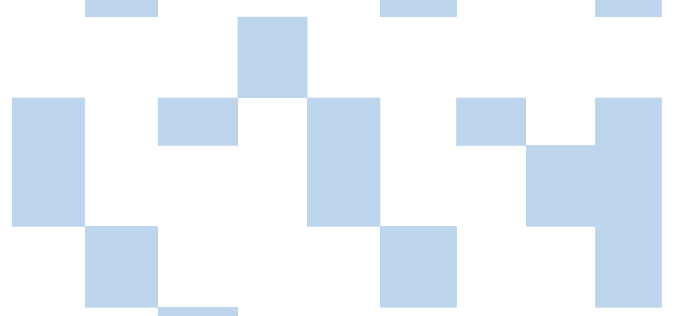


Table 1 Continued

\begin{tabular}{ll} 
Outcome category & Specific outcome \\
\hline $\begin{array}{l}\text { Outcome measures } \\
\text { related to the }\end{array}$ \\
$\begin{array}{l}\text { psychological aspects } \\
\text { of work }\end{array}$
\end{tabular}

\begin{tabular}{|c|c|c|}
\hline & Satisfaction & $\begin{array}{l}\text { Satisfaction with Work Scale (6- } \\
\text { item) })^{79}\end{array}$ \\
\hline & Well-being (work-related) & $\begin{array}{l}\text { Work engagement: Utrecht Work } \\
\text { Engagement Scale (3-items) }{ }^{80}\end{array}$ \\
\hline $\begin{array}{l}\text { Outcome measures } \\
\text { related to the physical }\end{array}$ & Physical capacity & $\begin{array}{l}\text { SF-12 Physical Component } \\
\text { Summary Score (5-items) }\end{array}$ \\
\hline & & HR record linkage \\
\hline & $\begin{array}{l}\text { Performance (productivity } \\
\text { and quality) }\end{array}$ & $\begin{array}{l}\text { The Conditions for Work } \\
\text { Effectiveness Questionnaire } \\
(19 \text {-items) })^{83}\end{array}$ \\
\hline Safety climate & $\begin{array}{l}\text { Measures attitudes and } \\
\text { perceptions towards safety } \\
\text { at a specific point in time }\end{array}$ & $\begin{array}{l}\text { The Multilevel Safety Climate Scale } \\
(16 \text {-items })^{85}\end{array}$ \\
\hline $\begin{array}{l}\text { Workplace } \\
\text { psychological safety }\end{array}$ & Psychological safety & $\begin{array}{l}\text { Psychologically safe workplace } \\
\text { questionnaire }(7 \text {-items })^{86}\end{array}$ \\
\hline $\begin{array}{l}\text { Health service quality } \\
\text { indicators }\end{array}$ & & Use organisational data \\
\hline $\begin{array}{l}\text { Medical and } \\
\text { medication errors }\end{array}$ & & Use organisational data \\
\hline Workplace accidents & & Use organisational data \\
\hline & Neighbourhood walkability & GIS-derived street connectivity \\
\hline & Neighbourhood cohesion & $\begin{array}{l}3 \text { questions in household, } \\
\text { sociodemographic and } \\
\text { neighbourhood section }\end{array}$ \\
\hline & $\begin{array}{l}\text { Neighbourhood } \\
\text { disadvantage }\end{array}$ & Socio-Economic Indices for Area \\
\hline & Geographic remoteness & $\begin{array}{l}\text { Modified Monash Model (Rurality) } \\
\text { ARIA }\end{array}$ \\
\hline
\end{tabular}

ADLs, Activities of Daily Living; ARIA, Accessibility/Remoteness Index of Australia; GIS, Geographic Information System; HR, Human Resources; SF12, Short Form-12.

\section{Participant consent}

One week after the prenotification email is delivered, all staff will be sent an email inviting them to participate in the study. The email will provide a link to access an online

\section{Study timepoint (months)}

\begin{tabular}{lllllllll}
\hline 0 & 3 & 6 & 9 & 12 & 15 & 18 & 24 & 30
\end{tabular}

Job Stress Scale (13-items) ${ }^{78}$

(1)

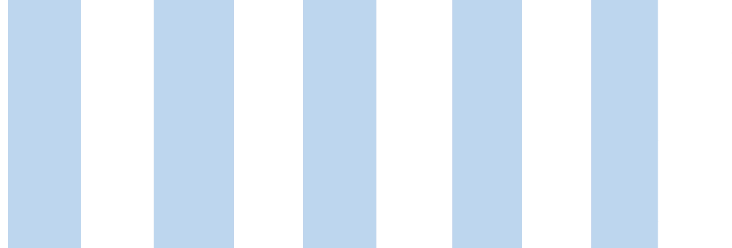

cally directed to the study 'landing and eligibility page'. Those who are eligible will be automatically directed to the participant information and consent form (PICF). All 
potential participants will be informed of the purpose of the study, confidentiality, their rights and how the information provided will be used. Potential participants will be asked if they consent (yes or no). If consent is denied, these people will be thanked for their time and be asked to complete a short eight-item questionnaire asking about their reasons for declining and some demographic characteristics. This will allow the characteristics of the questionnaire responders to be compared with the nonresponders to determine if non-response bias is likely to be an issue for the study. Those that provide consent will be automatically directed to complete the questionnaire. Potential participants will be given the option of consenting to participate in:

1. The current research study (yes or no).

2. Future research studies that may or may not be related to the current study (yes or no).

3. Linking of their study information with Victorian and National Health databases (yes or no).

Potential participants who do not respond will be sent several reminder emails. Each reminder email will include a link to the PICF and questionnaire. Those who initially provide consent but do not submit the completed questionnaire will also receive reminder emails as described above. There will be an ability for participants to save their questionnaire if it has not been completed and return to complete it later. Each follow-up questionnaire will be conducted in the same way as the baseline questionnaire with reminder emails also being sent to those who initially do not reply to the follow-up questionnaire. A summary of this recruitment strategy is outlined in figure 2 .

\section{Follow-up assessments}

Follow-up will be conducted two ways-using selfadministered online questionnaires and through record linkage to Victorian and National Health administration databases. Except for outcomes that do not usually change over time (eg, personality type), all follow-up questionnaires will readminister the same outcome measuring instruments used at baseline at regular intervals during follow-up so that change in important outcomes can be measured.

To reduce loss to follow-up, study participants will be offered an incentive at each follow-up timepoint in the form of a random draw to win a grocery voucher. A fridge magnet will also be provided to each participant as a reminder that they are a valued study participant. So that we are able to maintain contact with participants, the fridge magnet will also remind participants to contact the study team if they change their contact details. Participants will also be sent a newsletter every 6 months as a way of regularly engaging with participants, and as a means of updating them on important study developments and findings.

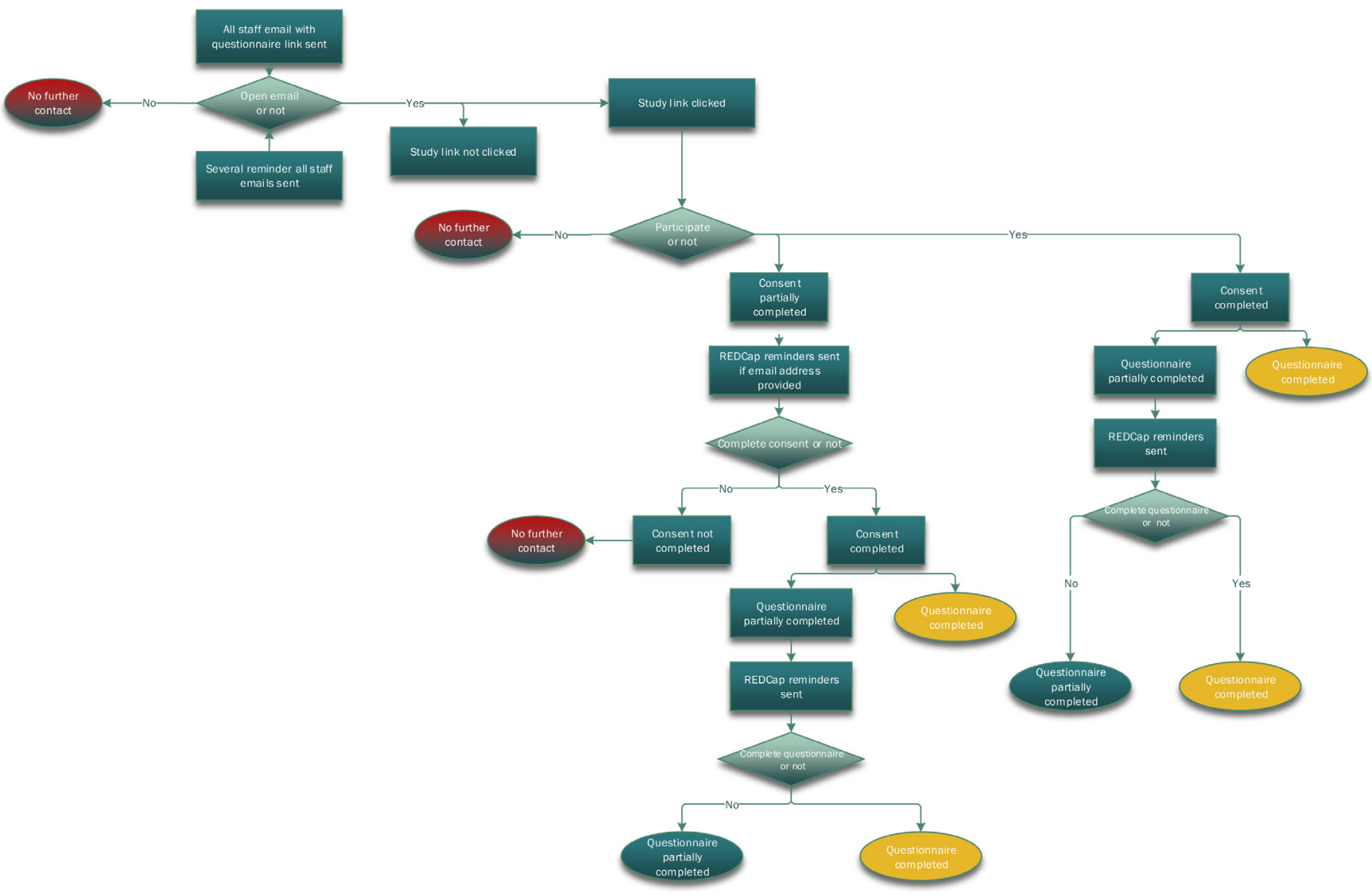

Figure 2 Graphical representation of the Loddon Mallee healthcare COVID-19 study recruitment strategy. 
Record linkage will be used to virtually follow the cohort over time to identify outcomes such as mortality, morbidity, hospital admissions, medication use and health service utilisation. With consent, questionnaire data will be linked with health administration databases including: Victorian Emergency Minimum Dataset, ${ }^{19}$ Victorian Admitted Episodes Dataset, ${ }^{20}$ Victorian Integrated Non-Admitted Health, ${ }^{21}$ Mental Health, ${ }^{22}$ Mental Health Community Support Services ${ }^{23}$ Victorian Cancer Registry, ${ }^{24}$ Victorian Death Index,${ }^{25}$ Elective Surgery Information System, ${ }^{26}$ Medical Radiation-Victorian Radiotherapy Minimum Dataset, ${ }^{27}$ Cause of Death Unit Record File, ${ }^{28}$ Australian Cancer Database, ${ }^{29}$ Medicare Benefits Schedule, ${ }^{30}$ Pharmaceutical Benefits Schedule ${ }^{31}$ and National Death Index. ${ }^{32}$

\section{Outcomes}

This study will serve as a platform for answering a myriad of research questions related to the effects of the COVID-19 pandemic on the health and well-being of the Victorian rural and regional healthcare workforce. Therefore, the study will examine multiple outcomes across the health and well-being continuum. There is no established 'core outcome set' (COS) for examining health and well-being of healthcare workers. COSs are important to ensure that research across populations is standardised to allow valid comparisons of study findings to be made. As such, an outcome taxonomy was created based on the WHO International Classification of Functioning, Disability and Health $^{33}$ and Williamson and Clarke taxonomies ${ }^{34}$ and constructed according to standards developed by the Core Outcome Measures in Effectiveness Trials initiative. ${ }^{35}$ These provide a framework to ensure that all important outcomes across the health and well-being continuum are measured, and informed the decision-making regarding the choice of outcome measurement instruments used in this study.

Study outcomes were categorised at an individual, organisation and community levels. At the individual level, outcomes consist of mortality, morbidity, clinical and physiological function, physical function, emotional health and well-being, cognitive function, social function, health-related quality of life, role function, personal circumstances, lifestyle, family function, and health service utilisation.

At an organisational level, outcomes include those related to the psychological aspects of work, physical aspects of work, work status and self-efficacy, safety climate, workplace psychological safety, health service quality indicators, COVID-19 training/infection control, and resource prioritisation.

At the community level, outcomes consist of access and use of support services, built environment, neighbourhood walkability, neighbourhood cohesion, neighbourhood disadvantage, and geographic remoteness.

The study outcomes and outcome measuring instruments are described in table 1 .

\section{Primary outcomes}

Although there are multiple study outcomes, the primary outcomes are emotional health and well-being and psychological resilience. The emotional health and wellbeing of healthcare workers will be measured at baseline and follow-up using self-administered online questionnaires. Emotional health and well-being will be measured using self-reported validated measures of well-being, generalised anxiety, fear of COVID-19, post-traumatic stress disorder, depressive symptoms, psychological stress, suicide ideation, resilience, mental fatigue, hope, selfefficacy, coping, worry, happiness, purpose, optimism, perceived control over life, childhood trauma, impact of life events, mindfulness, family history of mental disorder, and personality type.

\section{Secondary outcomes}

Secondary outcomes include mortality, morbidity, selfreported clinical and physiological function, physical function, cognitive function, social function, healthrelated quality of life, role function, personal circumstances, lifestyle, family function, health service utilisation, as well as organisational and community outcomes and these will be measured at baseline and follow-up using self-administered online questionnaires.

\section{Outcome measurement instruments}

The health and well-being outcomes will be measured at baseline and follow-up using validated instruments. The choice of outcome measurement instruments was determined using:

- Detailed review of existing literature focused on the study population in the context of previous pandemics and disasters.

- Evidence from published systematic reviews of outcome measuring instruments for each outcome.

- Consensus-based Standards for the selection of health Measurement Instruments database. ${ }^{36}$

- Evidence of superior psychometric properties and acceptability within the target population.

- Consultation with discipline-specific outcome experts.

- Discussion with lead researchers who have also developed COVID-19 research studies in healthcare workers.

- Consensus agreement between the study investigator team and the study scientific steering committee.

Given that there are many outcome measurement instruments, what follows is a summary of the instruments used to measure the primary outcomes-emotional health and well-being, and resilience. Emotional health and well-being will be measured using the following validated instruments: Personal Well-being Index-Adult, ${ }^{37}$ Generalised Anxiety Disorder-7,38 Fear of COVID-19 Scale,${ }^{39}$ Impact of Events Scale-6, ${ }^{40}$ Patient Health Questionnaire, ${ }^{41}$ Perceived Stress Scale, ${ }^{42}$ Suicidal Behaviours Questionnaire-Revised, ${ }^{43}$ Short Form-12 (SF-12) ${ }^{44}$ Adult State (Snyder) Hope Scale, ${ }^{45}$ General Self Efficacy Scale, ${ }^{46}$ Brief COPE, ${ }^{47}$ Penn State Worry Scale, ${ }^{48}$ Mental 
Health Continuum Short Form, ${ }^{49}$ Life Orientation TestRevised, ${ }^{50}$ Perceived Control Scale,${ }^{51}$ Childhood Trauma Questionnaire-Short Form, ${ }^{52}$ Mindfulness Attention Awareness Scale ${ }^{53}$ and Big 5 Inventory-Short Form. ${ }^{54}$

Resilience will be measured at baseline and follow-up in two ways- the validated Brief Resilience Scale ${ }^{55}$ and examining health states/outcomes considered to be markers of resilience (ie, healthy lifestyle behaviours, absence of morbidity, absence of psychological distress, etc.).

\section{Sociodemographic variables}

Sociodemographic variables include age, gender, education, marital status, household income, type of housing, number of people in household, postcode and number of dependents.

\section{Clinical and physiological variables}

Self-reported clinical, anthropometric and physiological variables include height, weight, resting pulse, systolic and diastolic blood pressure, somatic complaints, ${ }^{56}$ medical and surgical history, hearing, vision, presymptomatic screening, nutritional supplement use, age at menarche, age at menopause, number of pregnancies, age at each pregnancy, breastfeeding history, use of oral contraceptives and use of hormone replacement therapy.

\section{Lifestyle and lifestyle change variables}

Self-reported lifestyle behaviour variables include dietary consumption, physical activity, smoking tobacco, alcohol consumption, and sleep duration and quality.

Self-reported change in lifestyle behaviours due to the COVID-19 pandemic include change in diet, change in physical activity (time and intensity), change in sitting time, change in the frequency of meals/snacking, and change in sleep duration and quality.

\section{Employment background and work situation}

Occupational variables include employment status, type of healthcare setting and department/service, type of profession, number of years in profession, and absenteeism.

\section{COVID-19 pandemic-specific variables relating to the workplace}

Occupational variables assessing the impacts of the COVID-19 pandemic in the workplace include primary place of work during the pandemic, workplace redeployment, pandemic preparedness, COVID-19 infection control training, access and appropriate use of personal protective equipment (PPE), confidence in PPE training and contact with COVID-19 patients.

\section{COVID-19 pandemic-specific variables relating to individual health and well-being}

Variables assessing the impacts of the COVID-19 on the health and well-being of healthcare workers include impact of the pandemic of everyday life, COVID-19 testing history and status, hospitalisation due to COVID19, quarantine due to COVID-19, fear of contracting and transmitting COVID-19, effects of the pandemic on socialisation and travel, effects of the pandemic on relationships, effects of the pandemic on safety behaviours, and self-rated overall health during the pandemic.

\section{Potential positive experiences encountered during the COVID-19 lockdown}

Participants will be asked to reflect on any potential positive experiences that they may have encountered during the COVID-19 pandemic and lockdown. These variables include increased time spent with family, less workplace stress due to working at home, positive changes in relationships, more time to complete household projects, more time for hobbies, learning new skills, saving money and a new-found sense of gratitude for the freedoms that may have previously been taken for granted.

\section{Confounding variables}

As there are several research questions under investigation, the choice of confounding variables will depend on the research question under investigation and the potential causal relationship between the exposure and the outcome. Potential confounding variables include personal characteristics, organisational factors, social and personal lifestyle factors and community factors. Directed Acyclic Graphs ${ }^{57}$ will be used to determine potential confounders based on the traditional definition of a confounder ${ }^{58}$ For the primary aim of this study, the following potentially confounding variables will be considered in the analysis: sociodemographic factors (age, sex, marital status, income and education), family history of mental disorders, alcohol intake, tobacco smoking, physical activity, diet quality, sleep duration/quality, adverse life events, comorbidity, social support, and community neighbourhood social and ecological characteristics.

\section{Patient and public involvement}

There are no patients involved in this study. The participants were healthcare workers. Healthcare workers, as members of the study population were involved in the design and management of the study. We received input from healthcare workers who worked in the participating health services and associated organisations in the design of the study materials and management oversight through membership of the scientific steering committee. The burden on the study participants was assessed by administering the baseline questionnaire to a small group of healthcare workers who provided feedback on questionnaire length and impacts of specific questions.

We intend to disseminate the main findings to study participants and will seek their involvement in the development of an appropriate method of dissemination.

\section{Sample size}

Given that there are multiple study outcomes and no single hypothesis, the sample size for this study was determined based on a range of baseline exposure prevalence and outcome prevalence or incidence. Given a sample size of 4000 participants with statistical power of $80 \%$ and 
significance of level of $5 \%$, the minimal detectable effects for a range of baseline exposures and outcome prevalence vary between 1.2 and 2.1. With the same sample size and level of statistical significance, the minimal detectable effects for a range of baseline exposure prevalence and outcome incidence vary between 1.2 and 2.5. This is based on a range of outcome incidence over 3 years for those aged $18-65$ years.

\section{Statistical analysis plan}

Baseline descriptive characteristics of the sample will be described. Linear and logistic regression will be used to examine the association between participant characteristics measured at baseline with emotional health and well-being and resilience while adjusting for potentially confounding variables.

Participant characteristics measured at baseline will also be tested for association with incident health/disease/ mortality/health service utilisation outcomes at follow-up. Cox proportional hazard regression models will be used to investigate the association of baseline measures with each outcome at follow-up while adjusting for potential time-varying confounding variables. ${ }^{59}$

Latent growth curve modelling ${ }^{60}$ will be used to identify trajectories of psychological distress and resilience (eg, resilient, chronic distress, recovered and delayed recovery). Predictors and indicators of each class will then be examined by incorporating various indicators of resilience into the models. Missing data will be handled using best practice multiple imputation methodology. ${ }^{61}$

We agree that loss to follow-up can be expected in any cohort study. To reduce loss to follow-up, study participants will be offered an incentive at each follow-up timepoint in the form of a random draw to win a grocery voucher. A fridge magnet will also be provided to each participant as a reminder that are a valued study participant. The fridge magnet will also remind participants to contact the study team if they change their contact details. Participants will also be sent a newsletter every 6 months as a way of regularly engaging with participants and as a means of updating them on important study developments and findings.

Depending on the research question, loss to follow-up will be addressed using linear mixed models under the assumption of an immortal cohort with data missing at random. However, this is not appropriate if the data is missing not at random (MNAR). Therefore, a sensitivity analysis will be performed based on the assumption that data could be MNAR. In this case, a linear-increment model or joint modelling of longitudinal outcomes and time to death will be used. Under the assumption of a mortal cohort, inverse probability weighting or multiple imputation will be used. ${ }^{62}$

\section{Data management, storage and security}

An online REDCap database will store collected data. ${ }^{63} 64$ This database will be managed by an independent data manager. Study data will be kept securely on password protected computers at Bendigo Health and only the research team will know the password. Only the data manager will have access to a file with identifiable data. All data will be linked via an ID code. Linked data will be stored in a specific secure unified research environment developed by the Sax Institute ${ }^{65}$ as required by the Australian Institute of Health and Welfare and the Department of Health and Human Services.

\section{ETHICS AND DISSEMINATION}

\section{Ethics approval}

Ethics approval has been granted by the Bendigo Health (Review Reference LNR/20/BH/68671), La Trobe University (Reference 68671) and St John of God Healthcare (Reference 1746) Human Research Ethics Committees.

\section{Dissemination}

The study findings will be disseminated through international conferences, international peer-reviewed journals and social media.

\section{Protocol}

This study protocol is registered as a prospective cohort study on the Australian New Zealand Clinical Trials Registry (ANZCTR).

\section{Author affiliations}

${ }^{1}$ Rural Health School, La Trobe University, Bendigo, Victoria, Australia

${ }^{2}$ Research and Innovation, Bendigo Health, Bendigo, Victoria, Australia

${ }^{3}$ Executive Office, Kyabram District Health Service, Kyabram, Victoria, Australia

${ }^{4}$ Staff Development, Swan Hill District Health, Swan Hill, Victoria, Australia

Acknowledgements The authors would like to thank participating Loddon Mallee healthcare workers and volunteers for their support of this study. The authors thank the members of the Study Scientific Steering Committee who provided guidance and support for this study.

Contributors AC and MM initially designed the study with input from PF and AM. MM coordinated study set-up and finalisation of study questionnaire with CP, LB and GC. All authors (MM, AC, CP, LB, GC, PF, AM, SB and TS) contributed to questionnaire development and final study design in addition to editing and critiquing the final manuscript for intellectual content.

Funding This work was supported by COVID-19 Research grant provided by the Victoria Government Department of Jobs, Precincts and Regions.

Map disclaimer The inclusion of any map (including the depiction of any boundaries therein), or of any geographic or locational reference, does not imply the expression of any opinion whatsoever on the part of BMJ concerning the legal status of any country, territory, jurisdiction or area or of its authorities. Any such expression remains solely that of the relevant source and is not endorsed by BMJ. Maps are provided without any warranty of any kind, either express or implied.

Competing interests None declared.

Patient consent for publication Not required.

Provenance and peer review Not commissioned; externally peer reviewed.

Supplemental material This content has been supplied by the author(s). It has not been vetted by BMJ Publishing Group Limited (BMJ) and may not have been peer-reviewed. Any opinions or recommendations discussed are solely those of the author(s) and are not endorsed by BMJ. BMJ disclaims all liability and responsibility arising from any reliance placed on the content. Where the content includes any translated material, BMJ does not warrant the accuracy and reliability of the translations (including but not limited to local regulations, clinical guidelines, terminology, drug names and drug dosages), and is not responsible for any error and/or omissions arising from translation and adaptation or otherwise. 
Open access This is an open access article distributed in accordance with the Creative Commons Attribution Non Commercial (CC BY-NC 4.0) license, which permits others to distribute, remix, adapt, build upon this work non-commercially, and license their derivative works on different terms, provided the original work is properly cited, appropriate credit is given, any changes made indicated, and the use is non-commercial. See: http://creativecommons.org/licenses/by-nc/4.0/.

ORCID iD

Carol Parker http://orcid.org/0000-0002-0331-8351

\section{REFERENCES}

1 Sohrabi C, Alsafi Z, O'Neill N, et al. World Health organization declares global emergency: a review of the 2019 novel coronavirus (COVID-19). Int J Surg 2020;76:71-6.

2 Neill E, Meyer D, Toh WL, et al. Alcohol use in Australia during the early days of the COVID-19 pandemic: initial results from the COLLATE project. Psychiatry Clin Neurosci 2020;74:542-9.

3 Kisely S, Warren N, McMahon L, et al. Occurrence, prevention, and management of the psychological effects of emerging virus outbreaks on healthcare workers: rapid review and meta-analysis. BMJ 2020;369:m1642.

4 Buising KL, Williamson D, Cowie BC, et al. A hospital-wide response to multiple outbreaks of COVID-19 in health care workers: lessons learned from the field. Med J Aust 2021;214:101-104.e1.

5 Casigliani V, De Nard F, De Vita E, et al. Too much information, too little evidence: is waste in research fuelling the covid-19 infodemic? BMJ 2020;370:m2672

6 Chew QH, Wei KC, Vasoo S, et al. Narrative synthesis of psychological and coping responses towards emerging infectious disease outbreaks in the general population: practical considerations for the COVID-19 pandemic. Singapore Med J 2020;61:350-6.

7 Marvaldi M, Mallet J, Dubertret C, et al. Anxiety, depression, traumarelated, and sleep disorders among healthcare workers during the COVID-19 pandemic: a systematic review and meta-analysis. Neurosci Biobehav Rev 2021;126:252-64.

8 Lai J, Ma S, Wang Y, et al. Factors associated with mental health outcomes among health care workers exposed to coronavirus disease 2019. JAMA Netw Open 2020;3:e203976.

9 De Kock JH, Latham HA, Leslie SJ, et al. A rapid review of the impact of COVID-19 on the mental health of healthcare workers: implications for supporting psychological well-being. BMC Public Health 2021;21:104

10 Gilleen J, Santaolalla A, Valdearenas L, et al. Impact of the COVID-19 pandemic on the mental health and well-being of UK healthcare workers. BJPsych Open 2021;7:1-12.

11 Hao Q, Wang D, Xie M, et al. Prevalence and risk factors of mental health problems among healthcare workers during the COVID-19 pandemic: a systematic review and meta-analysis. Front Psychiatry 2021;12:567381.

12 Holton S, Wynter K, Trueman M, et al. Psychological well-being of Australian hospital clinical staff during the COVID-19 pandemic. Aust Health Rev 2021;45:297-305.

13 Toh WL, Meyer D, Phillipou A, et al. Mental health status of healthcare versus other essential workers in Australia amidst the COVID-19 pandemic: initial results from the collate project. Psychiatry Res 2021;298:113822.

14 Hammond NE, Crowe L, Abbenbroek B, et al. Impact of the coronavirus disease 2019 pandemic on critical care healthcare workers' depression, anxiety, and stress levels. Aust Crit Care 2021;34:146-54

15 Department of Health and Human Services. Public health workforce Melbourne: Victoria state government, 2020. Available: https:// vicknowledgebank.net.au/current-workforce/public-healthworkforce/ [Accessed 7 Jul 2021].

16 Victoria State Government. Victoria's Loddon Mallee Region: Regional Development Victoria, 2020. Available: https://www.rdv.vic. gov.au/victorias-regions/loddon-mallee [Accessed 18 Jan 2021].

17 Australian Government. Murray phn, 2020. Available: https://www. murrayphn.org.au/ [Accessed 18 Jan 2021].

18 Australian Government. Modified Monash Model - fact sheet: Department of Health, 2020. Available: https://www.health.gov. au/resources/publications/modified-monash-model-fact-sheet [Accessed 15 Feb 2021].

19 Victoria State Government. Victorian emergency minimum dataset (VEMD) Melbourne, Australia: department of health and human services, 2021. Available: https://www2.health.vic.gov.au/hospitalsand-health-services/data-reporting/health-data-standards-systems/ data-collections/vemd [Accessed 14 Jan 2021].
20 Victoria State Government. Victorian admitted episodes dataset. Melbourne, Australia: Department of Health and Human Services, 2021. https://www2.health.vic.gov.au/hospitals-and-health-services/ data-reporting/health-data-standards-systems/data-collections/ vaed

21 Victoria State Government. Victorian integrated Non-Admitted health. Melbourne, Australia: Department of Health and Human Services, 2021. https://www2.health.vic.gov.au/hospitals-and-health-services/ data-reporting/health-data-standards-systems/data-collections/ vinah

22 Victoria State Government. Service contact data definitions. Melbourne, Australia: Department of Health and Human Services, 2017. https://www2.health.vic.gov.au/ /media/Health/Files/ Collections/Factsheets/C/cmi-ods-community-activity-datadictionary-PDF

23 Victoria State Government. Mental health community support services Melbourne. Australia: Department of Health and Human Services, 2021. https://www2.health.vic.gov.au/mental-health/ mental-health-services/mental-health-community-support-services

24 Cancer Council Victoria. Victorian cancer registry Melbourne. Victoria: Cancer Council Victoria, 2021. https://www.cancervic.org. au/research/vcr/about-us

25 Victoria State Government. Research and data services Melbourne. Victoria: Births deaths and marriages Victoria, 2021. https://www. bdm.vic.gov.au/research-and-family-history/research-and-dataservices

26 Victoria State Government. Elective surgery information system. ESIS Melbourne, Australia: Department of Health and Human Services, 2021. https://www2.health.vic.gov.au/hospitals-andhealth-services/data-reporting/health-data-standards-systems/datacollections/esis

27 Victoria State Government. Victorian radiotherapy minimum data set user manual and appendices. Melbourne, Australia: Department of Health and Human Services, 2021. https://www2.health.vic.gov.au/ about/publications/policiesandguidelines/Victorian-Radiotherapyminimum-Data-set-User-Manual

28 Queensland Government. National death data Brisbane, Australia, 2020. Available: https://www.qld.gov.au/law/births-deathsmarriages-and-divorces/data/national-data [Accessed 14 Jan 2021].

29 Australian Government. Australian cancer database (ACD). Canberra Australia: Australian Institute of Health and Welfare, 2020. https:// www.aihw.gov.au/about-our-data/our-data-collections/australiancancer-database

30 Australian Government. Medicare benefits schedule (Mbs) data collection. Canberra, Australia: Australian Institute of Health and Welfare, 2020. https://www.aihw.gov.au/about-our-data/our-datacollections/medicare-benefits-schedule-mbs

31 Australian Government. Pharmaceutical benefits scheme (PBS) data collection. Canberra, Australia: Australian Institute of Health and Welfare, 2020. https://www.aihw.gov.au/about-our-data/our-datacollections/pharmaceutical-benefits-scheme

32 Australian Government. National death index (NDI). Canberra, Australia: Australian Institute of Health and Welfare, 2020. https:// www.aihw.gov.au/about-our-data/our-data-collections/nationaldeath-index

33 World Health Organisation. International classification of functioning, disability and health. Geneva, Switzerland, 2001.

34 Prinsen CAC, Vohra S, Rose MR, et al. How to select outcome measurement instruments for outcomes included in a "Core Outcome Set" - a practical guideline. Trials 2016;17:449-59.

35 Kirkham JJ, Davis K, Altman DG, et al. Core outcome Set-STAndards for development: the COS-STAD recommendations. PLoS Med 2017; 14:e1002447

36 Prinsen CAC, Mokkink LB, Bouter LM, et al. COSMIN guideline for systematic reviews of patient-reported outcome measures. Qual Life Res 2018;27:1147-57.

37 Cummins R, Lau A. Personal wellbeing Index-Adult. 5th Edn. Melbourne, Australia: Australian Centre on Quality of Life, Deakin University, 2013

38 Spitzer RL, Kroenke K, Williams JBW, et al. A brief measure for assessing generalized anxiety disorder: the GAD-7. Arch Intern Med 2006;166:1092-7.

39 Ahorsu D, Lin C, Imani V. The Fear of COVID-19 Scale> development and initial validation. Int J Ment Health Addict 2020:1-9.

40 Thoresen S, Tambs K, Hussain A et al. Brief measure of posttraumatic stress reactions: impact of event Scale-6. Soc Psychiatry Psychiatr Epidemiol 2010;45:405-12.

41 Kroenke K, Spitzer RL, Williams JB. The PHQ-9: validity of a brief depression severity measure. J Gen Intern Med 2001;16:606-13.

42 Cohen S, Kamarck T, Mermelstein R. A global measure of perceived stress. J Health Soc Behav 1983;24:385-96. 
43 Osman A, Bagge CL, Gutierrez PM, et al. The suicidal behaviors Questionnaire-Revised (SBQ-R): validation with clinical and nonclinical samples. Assessment 2001;8:443-54.

44 Ware J, Kosinski M, Keller SD. A 12-Item short-form health survey: construction of scales and preliminary tests of reliability and validity. Med Care 1996;34:220-33.

45 Snyder CR, Harris C, Anderson JR, et al. The will and the ways: development and validation of an individual-differences measure of hope. J Pers Soc Psychol 1991;60:570-85.

46 Schwarzer R, Jerusalem M. Generalized self-efficacy scale. Windsor, UK, 1995: 35-7.

47 Carver CS. You want to measure coping but your protocol's too long: consider the brief cope. Int J Behav Med 1997;4:92-100.

48 Hopko DR, Stanley MA, Reas DL, et al. Assessing worry in older adults: confirmatory factor analysis of the Penn state worry questionnaire and psychometric properties of an abbreviated model. Psychol Assess 2003;15:173-83.

49 Keyes CLM. Mental health in adolescence: is America's youth flourishing? Am J Orthopsychiatry 2006;76:395-402.

50 Scheier MF, Carver CS, Bridges MW. Distinguishing optimism from neuroticism (and trait anxiety, self-mastery, and self-esteem): a reevaluation of the life orientation test. J Pers Soc Psychol 1994;67:1063-78.

51 Bobak M, Pikhart H, Hertzman C, et al. Socioeconomic factors, perceived control and self-reported health in Russia. A crosssectional survey. Soc Sci Med 1998;47:269-79.

52 Bernstein DP, Stein JA, Newcomb MD, et al. Development and validation of a brief screening version of the childhood trauma questionnaire. Child Abuse Negl 2003;27:169-90.

53 Brown KW, Ryan RM. The benefits of being present: mindfulness and its role in psychological well-being. J Pers Soc Psychol 2003;84:822-48.

54 Soto CJ, John OP. Short and extra-short forms of the big five Inventory-2: the BFI-2-S and BFI-2-XS. J Res Pers 2017;68:69-81.

55 Smith BW, Dalen J, Wiggins K, et al. The brief resilience scale: assessing the ability to bounce back. Int J Behav Med 2008;15:194-200.

56 Attanasio V, Andrasik F, Blanchard EB, et al. Psychometric properties of the SUNYA revision of the psychosomatic symptom checklist. $J$ Behav Med 1984;7:247-57.

57 Shrier I, Platt RW. Reducing bias through directed acyclic graphs. BMC Med Res Methodol 2008;8:70.

58 Kamangar F. Confounding variables in epidemiologic studies: basics and beyond. Arch Iran Med 2012;15:508-16.

59 Ambrogi F, Biganzoli E, Boracchi P. Model-Based estimation of measures of association for time-to-event outcomes. BMC Med Res Methodol 2014;14:97.

60 Duncan T, Duncan S, Stryker L. An introduction to latent growth curve modelling, concepts, issues and applications. 2nd Edn. New Jersey, USA: Lawrence Erlbaum Associates, Inc, 2011.

61 Sterne JAC, White IR, Carlin JB, et al. Multiple imputation for missing data in epidemiological and clinical research: potential and pitfalls. BMJ 2009;338:b2393.

62 Jones M, Mishra GD, Dobson A. Analytical results in longitudinal studies depended on target of inference and assumed mechanism of attrition. J Clin Epidemiol 2015;68:1165-75.

63 Harris PA, Taylor R, Minor BL, et al. The REDCap Consortium: building an international community of software platform partners. $J$ Biomed Inform 2019;95:103208.

64 Harris PA, Taylor R, Thielke R, et al. Research electronic data capture (REDCap)--a metadata-driven methodology and workflow process for providing translational research informatics support. $J$ Biomed Inform 2009;42:377-81.

65 Sax Institute. Sure, secure unified research environment Glebe, NSW 2021. Available: https://www.saxinstitute.org.au/our-work/sure/ [Accessed 13 Jan 2021].
66 Raes F, Pommier E, Neff KD, et al. Construction and factorial validation of a short form of the Self-Compassion scale. Clin Psychol Psychother 2011;18:250-5.

67 Mezo PG. The self-control and self-management scale (SCMS): development of an adaptive self-regulatory coping skills instrument. J Psychopathol Behav Assess 2009;31:83-93.

68 Stewart A, Ware J, Sherbourne C. Psychological distress/well-being and cognitive functioning measures. Durham, NC: Duke University, 1992: 102-42.

69 Koenig HG, Westlund RE, George LK, et al. Abbreviating the Duke social support index for use in chronically ill elderly individuals. Psychosomatics 1993;34:61-9.

70 Hughes ME, Waite LJ, Hawkley LC, et al. A short scale for measuring loneliness in large surveys: results from two population-based studies. Res Aging 2004;26:655-72.

71 Craig CL, Marshall AL, Sjöström M, et al. International physical activity questionnaire: 12 -country reliability and validity. Med Sci Sports Exerc 2003;35:1381-95.

72 Bush K, Kivlahan D, McDonell M. The audit alcohol consumption questions (AUDIT-C): an effective brief screening test for problem drinking. Arch Intern Med 1998;158:1789-95.

73 Calle EE, Rodriguez C, Jacobs EJ, et al. The American cancer Society cancer prevention study II nutrition cohort. Cancer 2002;94:500-11.

74 Buysse DJ, Reynolds CF, Monk TH, et al. The Pittsburgh sleep quality index: a new instrument for psychiatric practice and research. Psychiatry Res 1989;28:193-213.

75 Marks G, Webb K, Rutishauser I. Monitoring food habits in the Australian population using short questions. Brisbane, Queensland: Australian Food and Nutrition Monitoring Unit, 2001.

76 Walker S, Sechrist K, Pender N. Health Promotion Model - instruments to measure health promoting lifestyle: HealthPromoting Lifestyle Profile (HPLP II) (adult version). J Nurs Res 1995;22:796-811.

77 Boterhoven de Haan KL, Hafekost J, Lawrence D, et al. Reliability and validity of a short version of the general functioning subscale of the McMaster family assessment device. Fam Process 2015;54:116-23.

78 Parker DF, DeCotiis TA. Organizational determinants of job stress. Organ Behav Hum Perform 1983;32:160-77.

79 Berube N, Gane M, Houlfort N. Validation of the satisfaction with work scale. Psychology 2007.

80 Schaufeli WB, Shimazu A, Hakanen J, et al. An ultra-short measure for work engagement. Eur J Psychol Assess 2019;35:577-91.

81 Kristensen TS, Borritz M, Villadsen E, et al. The Copenhagen burnout inventory: a new tool for the assessment of burnout. Work Stress 2005;19:192-207.

82 Gilbreath B LK. Supervisor behaviour and employee presenteeism. International Journal of Leadership Studies 2012;7:114-31.

83 Laschinger HK, Finegan J, Shamian J, et al. Impact of structural and psychological empowerment on job strain in nursing work settings: expanding Kanter's model. J Nurs Adm 2001;31:260-72.

84 Rigotti T, Schyns B, Mohr G. A short version of the occupational selfefficacy scale: structural and construct validity across five countries. $J$ Career Assess 2008;16:238-55.

85 Zohar D, Luria G. A multilevel model of safety climate: cross-level relationships between organization and group-level climates. $J$ Appl Psychol 2005;90:616-28.

86 Edmondson A. Psychological safety, trust and learning in organizations: a group=level lens. Russell Sage Foundation, 2004: 239-72.

87 Van Bel D, Smoders K, ljsselsteijn A. Social connectedness: concept and measurement. International conference on intelligent environments, 2009:67-74.

88 Higginbotham N, Connor L, Albrecht G, et al. Validation of an environmental distress scale. Ecohealth 2007:3:245-54. 